\title{
Late Onset, Prolonged Asystole Following Organophosphate Poisoning: A Case Report
}

\author{
Jose Chacko • Ashok Elangovan
}

Published online: 8 June 2010

(C) American College of Medical Toxicology 2010

\begin{abstract}
Introduction Organophosphate (OP) compounds are commonly used as suicidal agents and produce characteristic toxic effects. Cardiac arrhythmias are often observed in the acute phase of toxicity; late onset polymorphic ventricular tachycardia preceded by prolonged QT interval on the EKG is also known to occur. However, there are no reports of late onset, prolonged asystole without preceding arrhythmias and after acute toxicity had abated.

Case Report We report a case of prolonged asystole 12 days after ingestion of an OP compound, after apparent recovery from the acute toxic effects. Asystole persisted for $25 \mathrm{~min}$, followed by successful resuscitation without any sequelae. Discussion Although cardiac arrhythmias and circulatory arrest are known to occur following OP ingestion, these are often in the acute phase of toxicity. Our patient had no preceding cardiac manifestations but developed prolonged refractory asystole after 12 days of ingestion of the compound when the acute effects had subsided. We emphasize the importance of being aware of the potential for OP compounds to cause late onset asystole and the need for continued EKG monitoring even after the acute symptoms appear to have settled.
\end{abstract}

Keywords Organophosphate $\cdot$ Late onset $\cdot$ Asystole

Source of funding None

Previous presentation of data Not presented

J. Chacko $(\bowtie) \cdot$ A. Elangovan

Manipal Hospital,

Bangalore PIN: 560017, India

e-mail: chackojose@gmail.com

\section{Introduction}

Organophosphate (OP) compounds, widely used as pesticides, are powerful inhibitors of the acetylcholinesterase enzyme and commonly used as a suicidal agent in many parts of the world. There is also an ever-increasing threat globally from similar agents, known popularly as "nerve gas", being used in chemical warfare and terrorist attacks. These chemicals belong to the same class and produce similar clinical effects when inhaled. Excessive cholinergic activity results in characteristic symptoms - increased salivation, bronchorrhea, sweating, pinpoint pupils with muscle fasciculations, and paralysis resulting in respiratory failure with severe poisoning [1]. However, the late onset cardiac effects of OP toxicity may be less appreciated. Sudden onset asystole after recovery from acute toxic effects has not been reported. We report a case of prolonged asystole followed by successful resuscitation in a young man 12 days after he had consumed an OP compound.

\section{Case Report}

A 25-year-old man presented to us $2 \mathrm{~h}$ after consuming about $100 \mathrm{ml}$ of $50 \%$ methyl parathion. He had been severely depressed in the preceding weeks because he had incurred heavy financial losses from his business ventures. He was treated elsewhere with gastric lavage and atropine before being transferred to our emergency department. There were obvious signs of significant poisoning with copious oral and bronchial secretions. His butyrylcholinesterase level was $1,943 \mathrm{IU} / \mathrm{ml}$ (normal range $=5,900$ $12,220 \mathrm{IU} / \mathrm{ml})$. He was commenced on an atropine infusion titrated to between 1.0 and $3.0 \mathrm{mg} / \mathrm{h}$. However, he became progressively weak with inability to cough out secretions 
and hence was intubated and put on mechanical ventilation a day after admission to our intensive care unit. Atropine infusion was continued, on which he had a sinus tachycardia ranging between 120 and 130 beats/min. He was also commenced on subcutaneous enoxaparin for thromboprophylaxis, intravenous pantoprazole for stress ulcer prophylaxis, and enteral nutrition. According to our unit policy, we did not put him on oxime therapy. He maintained stable blood pressures and renal function all along. His EKG did not show any abnormalities and the corrected QT interval (QTc) was $0.38 \mathrm{~s}$. A tracheostomy was done on day 5 as he continued to have large amounts of bronchial secretions and a weak cough. By day 8 , his secretions had dried up significantly and he was able to breathe without ventilatory assistance through a "T" piece. He remained fully awake, communicative, and was remorseful of his actions.

On day 12 of admission, he was breathing spontaneously without obvious discomfort; his arterial blood gas analysis done in the morning showed a $\mathrm{pH}$ of 7.46, $\mathrm{pCO}_{2}$ : $38.7 \mathrm{mmHg}, \mathrm{pO}_{2}: 173 \mathrm{mmHg}$, and a base excess of $1.2 \mathrm{mmol} / \mathrm{l}$. His serum sodium was $135 \mathrm{mEq} / \mathrm{l}$ and potassium $3.7 \mathrm{mEq} / \mathrm{l}$. He was being maintained on an atropine infusion at $1 \mathrm{mg} / \mathrm{h}$, and was in sinus rhythm with a heart rate of around 100 beats/min; besides, he was also on enoxaparin and pantoprazole. By afternoon, he became progressively more tachycardic (140 beats/min); however, his blood pressures remained stable. The QTc at that time was $0.38 \mathrm{~s}$. Over the next few minutes, his QRS complex was noted to become progressively wider (Fig. 1); however, his blood pressure continued to remain stable. Over the next few seconds, the QRS complexes widened further, culminating in a run of pulseless ventricular tachycardia (VT) (Fig. 2) for about 10 beats. Before defibrillation could be attempted, he rapidly progressed to asystole. Cardiopulmonary resuscitation (CPR) was commenced and $1 \mathrm{mg}$ of adrenaline was administered intravenously. After 2 min of

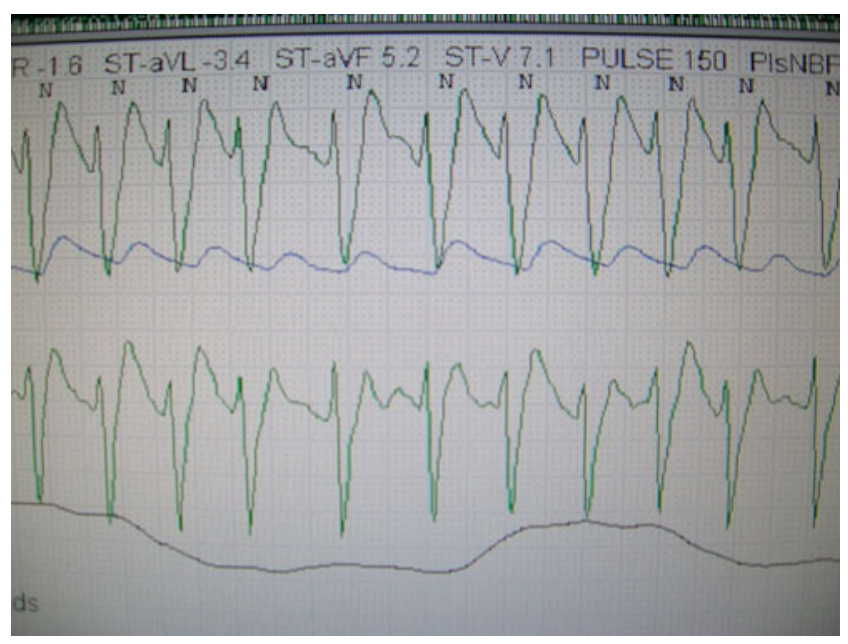

Fig. 1 Wide QRS complexes

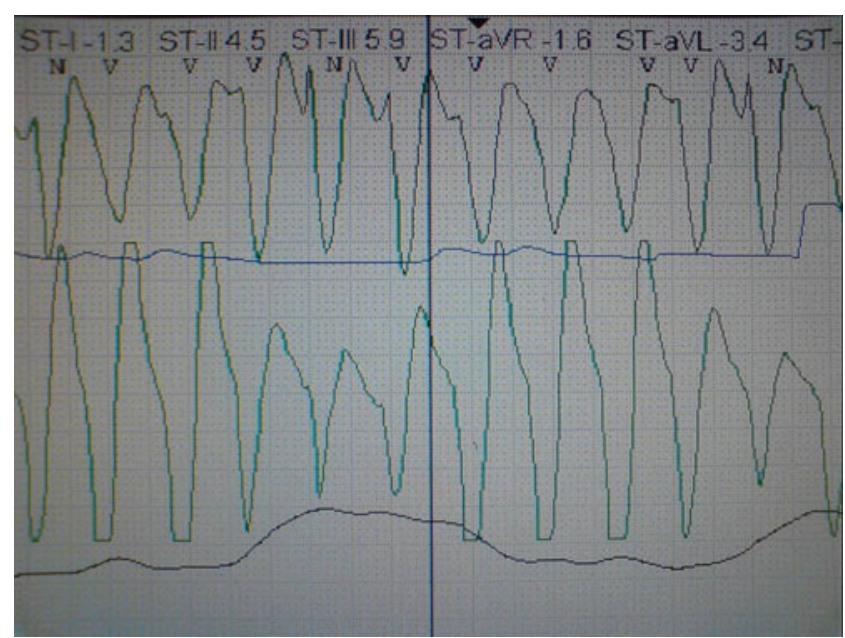

Fig. 2 Ventricular tachycardia

CPR, he continued to be in asystole. CPR was continued, interrupted only for a few seconds each time for rhythm assessment, in addition to multiple doses of adrenaline, atropine, and sodium bicarbonate. However, no electrical activity was discernible on the EKG trace for the next $25 \mathrm{~min}$. A venous blood gas analysis done about $15 \mathrm{~min}$ into resuscitation revealed a $\mathrm{pH}$ of $6.9, \mathrm{pCO}_{2}$ of $68 \mathrm{mmHg}$, $\mathrm{pO}_{2}$ of $46 \mathrm{mmHg}$, and a base excess of $-18 \mathrm{mmol} / \mathrm{l}$. His blood sugar was $248 \mathrm{mg} / \mathrm{dl}$, sodium $146 \mathrm{mEq} / \mathrm{l}$, potassium $6.5 \mathrm{mEq} / \mathrm{l}$, and magnesium $2.1 \mathrm{mEq} / 1$ at that time. After $25 \mathrm{~min}$, he developed a wide complex rhythm without a pulse; defibrillation was attempted with $200 \mathrm{~J}$ of biphasic current, followed by CPR. After another $2 \mathrm{~min}$, he continued to be in a wide complex rhythm. However, a carotid pulse was palpable at this stage and a blood pressure of $72 / 38 \mathrm{~mm} \mathrm{Hg}$ was recorded from the arm. A bolus dose of amiodarone $150 \mathrm{mg}$ followed by an infusion at $900 \mathrm{mg} /$ $24 \mathrm{~h}$ was commenced. Over the next few minutes, the QRS complexes became normal, and the rhythm settled down to a sinus tachycardia of about 110 beats/min. An EKG done immediately after resuscitation showed sinus tachycardia of 110 beats/min and a QTc of $0.4 \mathrm{~s}$ with no ST-T changes. The echocardiogram revealed normal left ventricular function with normal-sized chambers and no regional wall motion abnormalities. About $2 \mathrm{~h}$ after resuscitation, he was fully awake, appropriate, and able to communicate. We stopped the amiodarone infusion after $24 \mathrm{~h}$. His QRS complexes and QTc remained normal after the event. We followed him up with daily 12-lead EKGs-early repolarization abnormalities were noted on one occasion which, however, reverted back to normal in less than $24 \mathrm{~h}$. Our patient continued to make steady improvement; he was decannulated and subsequently discharged home after 26 days of hospital stay. Neuropsychiatric testing done prior to discharge revealed no derangement of his intellectual function. On detailed questioning after the event, we 
obtained no history of sudden deaths or symptoms suggestive of irregular heart rhythm in any other member of the family.

\section{Discussion}

Cardiac toxicity after OP compounds may occur in three phases [2]. Initially, there is a brief period, usually lasting for a few minutes, of intense sympathetic activity, characterized by tachycardia and hypertension, considered to be a nicotinic effect. This is followed by a more prolonged period of extreme cholinergic activity during which bradycardia and hypotension along with ST-T changes and life-threatening rhythm disturbances can occur. A third, longer phase is usually associated with a prolonged QT interval and polymorphic VT that can result in sudden death. This phase can appear as early as a few hours after ingestion for up to as long as 15 days when other signs of toxicity have apparently settled down.

Luzhnikov et al., in their series of 183 patients, pointed out that life-threatening arrhythmias can occur with OPs, sometimes several days after ingestion [3]. Thirty four patients developed arrhythmias or conduction disturbances; all were associated with a prolonged QT interval. Twenty one patients went on to develop multifocal ventricular ectopics that progressed to ventricular fibrillation (VF). A total of 29 patients died within the first 6 days, most of them with VF. There are other reports of prolonged QT interval culminating in polymorphic VT following OP ingestion [4-6].

In another study, EKG changes were noted in 134 out of 168 patients with OP poisoning. Various types of arrhythmias occurred in 56 patients, from 1 to 20 days after exposure. These included premature ventricular contractions, VT and VF [7].

Saadeh et al., in a retrospective analysis of 46 patients with OP poisoning, noted a prolonged QT interval in 31 (67\%) patients. Four patients developed monomorphic VT of whom two progressed to VF; both died in spite of resuscitative measures. Asystole was not reported as the primary arrest rhythm in any patient in this study [8].

A combination of ST-T changes and low voltage complexes or progressive drop in voltage carried adverse prognostic significance in the study by Dalvi et al. Twelve out of 17 patients who had these changes died in their study of 123 patients. In the survivors, the EKG took a longer period of time to reverse. Other EKG abnormalities included prolonged QT interval, ectopic beats, and tall $\mathrm{p}$ waves; these did not correlate with clinical outcomes [9]. In a cohort of 85 patients with OP poisoning, QT prolongation was the most common EKG abnormality, followed by sinus tachycardia. VT or cardiac asystole was not observed in any of these patients [10].
The mechanism of cardiac toxicity induced by OP compounds is unclear. A direct toxic effect on the heart, unrelated to deficient acetylcholinesterase activity and uninfluenced by atropine administration, has been postulated. This effect may be dose related [11]. Another possibility is that extreme parasympathetic stimulation of the myocardium through excessive acetylcholine release might result in significant damage to the heart [12, 13]. Excess acetylcholine may also cause coronary vasoconstriction in normal and atherosclerotic coronary arteries [14]. However, this mechanism may not explain the late onset of arrhythmias and ST-T changes that appear once the cholinergic phase has abated. Rise in free fatty acid levels seen after organophosphate ingestion have been implicated in the causation of arrhythmias by some authors [7]. Late onset arrhythmias may also represent the onset of the healing process and recovery in a damaged myocardium [15]. Anand et al. aimed to correlate cardiac physiology with EKG and echocardiographic findings in their series of 36 patients. Although seven patients developed prolongation of the QT interval, none of them went on to develop VT or VF. The left ventricular systolic function was normal on echocardiogram on all patients. Myocardial blotchiness, patchy pericarditis, subepicardial hemorrhage, and hemorrhages on the posterior aspect of the left ventricle and left atrium were observed in three cases. The authors attributed this to early myocardial toxicity, although some of these changes could have been due to attempted CPR [16].

Our patient had made substantial improvement in the 12 days following ingestion. He had regained muscle strength to a large extent and had little evidence of excessive cholinergic activity at the time of the event. The QT interval was normal on the initial EKG at admission and he was on no medication that could predispose to prolongation of the QT interval. He developed progressively wide QRS complexes followed by a short burst of VT that culminated in asystole, all within a period of about 3 min. His 12-lead EKG was totally normal on admission, and there were no abnormalities noticed during the time he was in the intensive care unit. We analyzed his EKG recording stored in our central monitors during the $96 \mathrm{~h}$ preceding the event. He was in sinus tachycardia throughout; there were no ectopic beats noted. There were no ST-T changes and the QT interval was within normal limits throughout this period. Our patient was breathing comfortably on a $\mathrm{T}$ piece, fully awake, and saturating well at the time of the event. His potassium level was normal when last done about $5 \mathrm{~h}$ prior to the arrest; during resuscitation, it rose to 6.5 , which was probably due to prolonged CPR and significant metabolic acidosis [17].

Although others have reported dangerous arrhythmias several days after OP ingestion after the acute signs of toxicity had abated, these were preceded by EKG 
abnormalities, notably, prolongation of the QT interval [7]. In our search of literature, we did not come across any instance where asystole occurred as the primary arrest rhythm 12 days after OP ingestion without any preceding EKG changes.

We considered acute massive pulmonary embolism in our patient. However, this seemed unlikely given that he regained hemodynamic stability once sinus rhythm was re-established, suggesting that the problem was rhythm related. Besides, he never had a wide alveolar to arterial oxygen tension gradient, which is usually a feature of massive pulmonary embolism; nor did he have corroboratory EKG or echocardiographic changes. Acute coronary syndrome would also seem extremely unlikely, given his age, the absence of EKG changes, and a normal echocardiogram post event. Our patient was not on any medication that might have caused prolongation of the QT interval and polymorphic VT; he had a normal QT interval prior to and after the episode.

Our patient was in asystole for $25 \mathrm{~min}$; we persisted with resuscitative efforts because there was no obvious irreversible underlying problem apart from the toxin itself. It is remarkable that our patient suffered no trace of hypoxic brain injury even after such a long time to return of spontaneous circulation. CPR of longer than 20 min duration is generally associated with poor outcomes [18]. We believe that uninterrupted, effective CPR was probably responsible for the good outcome in our case. There have been other reports of complete neurological recovery after cardiotoxic drugs, especially calcium channel blockers [19-21].

In summary, we report a 25 -year-old man who developed asystolic cardiac arrest, following a short run of VT, 12 days after ingestion of an OP compound. At the time of the event, he was well on the way to recovery from the severe muscular weakness that he had presented with. Throughout his ICU stay preceding the event, there were no EKG abnormalities noted, except for sinus tachycardia. He remained in asystole for $25 \mathrm{~min}$ and, after a brief period of wide complex arrhythmia, returned to spontaneous circulation and stable hemodynamic parameters. He suffered no neurological insult in the process and made a complete recovery from the effects of the toxin. It is important to emphasize that late onset cardiac complications can occur after OP poisoning, even when other toxic effects have reversed; asystole can occur as the primary arrest rhythm in such patients. A longer duration of EKG monitoring seems warranted, even after the acute toxic effects appear to have settled down. Efforts at resuscitation should probably be persisted with for a longer duration in such cases as there is usually no underlying irreversible problem apart from the toxin itself, the effects of which could disappear with time and continued supportive care.

\section{References}

1. Sidell FR (1994) Clinical effects of organophosphorus cholinesterase inhibitors. J Appl Toxicol 14(2):111-113

2. Ludomirsky A, Klein H, Sarelli P, Becker B, Hoffman S, Thitelman U et al (1982) QT prolongation and polymorphous ("torsade de pointes") ventricular arrhythmias associated with organophosphate insecticide poisoning. Am J Cardiol 49:16541658

3. Luzhnikov EA, Savina AS, Shepelev VM (1975) On the pathogenesis of cardiac rhythm and conductivity disorders in cases of acute insecticide poisoning. Kardiologiia 15:126-129

4. Wang MH, Tseng CD, Bair SY (1998) QT interval prolongation and pleomorphic ventricular tachyarrhythmia ("Torsade de pointes') in organophosphate poisoning: report of a case. Hum Exp Toxicol 17:587-590

5. Rubinshtein R, Bar-Meir E, Grubstein A, Bitterman H (2002) Early onset of ventricular tachyarrhythmias in organophosphate intoxication. IMAJ 4:63-64

6. Karki P, Ansari JA, Bhandary S, Koirala S (2004) Cardiac and electrocardiographical manifestations of acute organophosphate poisoning. Singapore Med J 45:385-389

7. Kiss Z, Fazekas T (1979) Arrhythmia in organophosphate poisoning. Acta Cardiol 34:323-330

8. Saadeh AM, Farsakh NA, Al-Ali MK (1997) Cardiac manifestations of acute carbamate and organophosphate poisoning. Heart 77:461-464

9. Dalvi CP, Abraham PP, Iyer SS (1986) Correlation of electrocardiographic changes with prognosis in organophosphorus poisoning. J Postgrad Med 32:115-119

10. Yurumez Y, Yavuz Y, Saglam H, Durukan P, Ozkan S, Akdur O et al (2009) Electrocardiographic findings of acute organophosphate poisoning. J Emerg Med 36:39-42

11. Marosi G, Ivan J, Vass K, Gajdacs A, Ugocsai G (1989) EKG repolarizations Zavar (QT megnyulas) ViZsgalata zserves foszforsaveszter mergezesben. Orv Hetil 130:111-115

12. Manning GW, Hall GE, Banting FG (1937) Vagus stimulation and the production of myocardial damage. Can Med Assoc J 37:314 318

13. Hall GE, Ettinger GH, Banting FG (1936) An experimental production of coronary thrombosis and myocardial failure. Can Med Assoc J 34:9-15

14. Horio Y, Yasue H, Bokutanda M, Nakamura N, Ogawa H, Takaoka $\mathrm{K}$ et al (1986) Effects of intracoronary injection of acetylcholine on coronary arterial diameter. Am J Cardiol 57:984-989

15. Roth A, Zellinger I, Arad M, Atsmon J (1993) Organophosphates and the heart. Chest 103:576-582

16. Anand S, Singh S, Saikia UN, Bhalla A, Sharma YP, Singh D (2009) Cardiac abnormalities in OP poisoning. Clin Toxicol 47:230-235

17. Martin GB, Nowak RM, Cisek JE, Carden DL, Tomlanovich MC (1989) Hyperkalemia during human cardiopulmonary resuscitation: incidence and ramifications. J Emerg Med 7:109-113

18. Schultz SC, Cullinane DC, Pasquale MD, Magnant C, Evans SRT (1996) Predicting in-hospital mortality during cardiopulmonary resuscitation. Resuscitation 33:13-17

19. Evans JS, Oram MP (1999) Neurological recovery after prolonged verapamil-induced cardiac arrest. Anaesth Intensive Care 27:653655

20. Holzer M, Sterz F, Schoerkhuber W (1999) Successful resuscitation of a verapamil-intoxicated patient with percutaneous cardiopulmonary bypass. Crit Care Med 27:2818-2823

21. Waxman AB, White KP, Trawick DR (1997) Electromechanical dissociation following verapamil and propranolol ingestion: a physiologic profile. Cardiology 88:478-481 